\title{
ANÁLISE DA PROTEÇÃO DAS PATENTES SEGUNDO A LEI BRASILEIRA
}

\author{
Luis Fernando Lisboa Humphreys ${ }^{1}$
}

\section{INTRODUÇÃO}

A proteção da propriedade intelectual é tema corrente em Direito Internacional, pois as idéias e inventos circulam com facilidade para além das fronteiras nacionais. Há a necessidade de proteção universal da propriedade intelectual, para que seja mantido o seu valor econômico.

A matéria é tratada desde o século XIX por convenções internacionais, das quais são partes integrantes a grande maioria dos países existentes. 0 intuito destas convenções é o de uniformizar as garantias mínimas atinentes à propriedade intelectual e o de criar leis modelos para os países aderentes. A lei brasileira sobre o assunto se insere neste contexto, reproduzindo internamente as diretivas gerais dos acordos internacionais.

Este artigo concentra-se na análise estrita da lei brasileira, desconsiderando os instrumentos internacionais, visto que a racionalidade de ambos é idêntica e que a maioria dos direitos conferidos no plano internacional também o são no plano interno. Mais especificamente, será tratada apenas a matéria referente às patentes e modelos de utilidade, excluindo da análise outros elementos específicos da propriedade intelectual, tais como as marcas e as denominações de origem. Os tópicos apresentados a seguir possuem a mesma ordem lógica dada pela Lei ํํ 9.279/1996.

\section{PATENTEABILIDADE}

"Patente é um título de propriedade temporário que contém importantes informações tecnológicas"², assegurando direitos sobre invenções e modelos de utilidade.

\footnotetext{
${ }^{1}$ Advogado, formado pela Universidade Federal do Paraná, participante do Núcleo de Direito Internacional - Propriedade Intelectual, da UFPR.
}

Revista Brasileira de Direito Internacional, Curitiba, v.4, n.4, jul./dez.2006 
A patenteabilidade da invenção e do modelo de utilidade depende de três requisitos básicos: novidade, atividade inventiva e aplicação industrial. ${ }^{3}$

A lei ${ }^{4}$ define como nova, toda invenção que não está compreendida no estado da técnica.

\begin{abstract}
"O estado da técnica abrange, de início, todos os conhecimentos a que pode ter acesso qualquer pessoa, especialmente os estudiosos de um assunto em particular, no Brasil ou no exterior. São alcançados pelo conceito os conhecimentos divulgados por qualquer meio, inclusive o oral e o cibernético, na data em que o inventor submete a sua invenção ao INPI (depósito do pedido de patente). Se o objeto reivindicado pelo inventor já se encontra acessível, nestes termos, a qualquer outra pessoa, então lhe falta o requisito da novidade. Não caberá a proteção do direito industrial, porque, se a correspondente descrição já se encontra divulgada, o requerente não pode ser tido como o primeiro a inventar o objeto. Também se consideram integrantes do estado da técnica alguns conhecimentos não divulgados. São os descritos em patente depositada, ainda não publicada."
\end{abstract}

Em contrapartida, podem alguns conhecimentos já publicados serem excluídos do conceito de estado da técnica, de modo a preservar o elemento da novidade. Isto ocorre quando o próprio autor divulga sua invenção antes do depósito, ou quando terceiro, sem sua autorização, o faz. Nestes casos, a divulgação não pode ter sido realizada há mais de 12 (doze) meses antes do depósito, sob pena de ser considerada como integrante do estado da técnica.

O segundo elemento da invenção, a atividade inventiva, tem seu conceito dado pela Lei de Patentes (art. 13), que afirma que "a invenção é dotada de atividade inventiva sempre que, para um técnico no assunto, não decorra de maneira evidente ou óbvia do estado da técnica". Deve haver, portanto, certo grau de trabalho e criatividade para que haja atividade inventiva.

\footnotetext{
2 PIMENTEL, Luiz Otávio. Propriedade Intelectual e Universidade. Florianópolis: Fundação Boiteux, 2005. p. 39.

${ }^{3}$ Parte da doutrina (COELHO, Fábio Ulhoa) entende que existe um quarto elemento, o do "desimpedimento". Todavia, como o próprio nome sugere, e como o próprio autor reconhece, isto não é parte um elemento intrínseco da invenção, mas diz respeito aos valores disseminados na sociedade. Por isso, serão os impedimentos à patenteabilidade tratados em tópico separado, como categoria própria, alheia aos elementos concessivos da patente. ${ }^{4}$ Lei 9.279/1996, art. 11.

${ }^{5}$ COELHO, Fábio Ulhoa. Curso de Direito Comercial, vol 1, 7aㅡ ed.. São Paulo: Saraiva, 2003. p. 150.
}

Revista Brasileira de Direito Internacional, Curitiba, v.4, n.4, jul./dez.2006 
O terceiro elemento da patenteabilidade é a aplicação industrial. A aplicação é tomada no sentido amplo, não precisando ser imediata ou economicamente viável.

Mesmo que uma invenção ou modelo contenha os requisitos da novidade, atividade inventiva e aplicação industrial, não é patenteável aquilo "que for contrário à moral, os bons costumes e à segurança, à ordem e à saúde pública". ${ }^{\circ}$

Semelhantemente, são excluídos do conceito de invenção ou modelo de utilidade, de antemão, por força do art. 10 da Lei 9.279/96: "I - as descobertas, teorias científicas e métodos matemáticos; II - concepções puramente abstratas; esquemas, planos, princípios ou métodos comerciais, contábeis financeiros, educativos, publicitários, de sorteio e de fiscalização; IV - obras literárias, arquitetônicas, artística e científicas ou qualquer criação estética; V - programas de computador em si; VI - apresentação de informações; VII - regras de jogo; VIII - técnicas e métodos operatórios ou cirúrgicos, bem como métodos terapêuticos ou de diagnósticos, para a aplicação no corpo humano ou animal; e IX - o todo ou parte de seres vivos naturais e materiais biológicos encontrados na natureza, ou ainda que dela isolados, inclusive o genoma ou germoplasma de qualquer ser vivo natural e os processos biológicos naturais".

Neste ponto, merece destaque o inciso IX, que veda apenas a patente dos organismos encontrados na natureza, abrindo a possibilidade de patente sobre organismos geneticamente modificados pela atividade humana e que obedeçam aos três critérios elementares da concessão da patente. ${ }^{7}$

\section{TITULARIDADE E PROTEÇÃO CONFERIDAS PELAS PATENTES}

A titularidade da patente é conferida ao autor que primeiro depositar o pedido perante o Instituto Nacional da Propriedade Industrial (INPI), desconsiderando-se se outro autor realizou a invenção em período anterior.

\footnotetext{
${ }_{7}^{6}$ Art. 18, I, da Lei 9.279/96.

${ }^{7}$ A possibilidade de patentear organismos transgênicos é expressamente reconhecida no art. 18 , III.
}

Revista Brasileira de Direito Internacional, Curitiba, v.4, n.4, jul./dez.2006 
Além disso, o pedido de patente gera presunção juris tantum de que o requerente é o legítimo autor, não havendo necessidade de qualquer comprovação sobre a autoria do invento.

O titular tem o direito de impedir o uso, produção, venda e importação do objeto da patente por terceiros sem sua autorização. A proteção se estende, inclusive, à possibilidade de impedimento para que terceiros contribuam para que outros pratiquem tais atos.

A proteção das patentes também goza de benefício processual. "Em caso de violação de patente de processo de fabricação, compete ao acusado o ônus de provar que seu produto foi obtido por processo diverso do protegido pela patente."

Excluem-se da proteção da patente as hipóteses em que o objeto é utilizado sem autorização do titular, mas I - em caráter privado, sem finalidade comercial; II - com finalidade experimental, relacionada a estudos ou a pesquisas; III - relaciona-se à produção individual de medicamentos, por profissional habilitado; IV - tratando-se de patente sobre matéria viva, utilize 0 objeto patenteado sem finalidade econômica e como fonte inicial de variação ou propagação para obter outros produtos. ${ }^{9}$

A lei ainda assegura ao terceiro, usuário de boa-fé, que antes da data do depósito já explorava seu objeto, o direito de continuar a exploração econômica, sem quaisquer ônus. Entretanto, a ele é vedado ceder este direito, a não ser que em conjunto com o negócio ou empresa que o explora.

\section{PROCESSO DE CONCESSÃO DE PATENTES}

A proteção do direito à propriedade industrial depende do registro da patente no INPI (Instituto Nacional de Propriedade Industrial), o qual é

\footnotetext{
${ }^{8}$ SILVEIRA, Newton. A propriedade Intelectual e as novas leis autorais. $2^{\underline{a}}$ ed. São Paulo: Saraiva, 1998. p. 43.

${ }^{9} \mathrm{O}$ art. 43 da Lei $9.279 / 96$ enumera outras hipóteses de exclusão de proteção, mas que já se encontram protegidas genericamente pela sistemática da lei.
}

Revista Brasileira de Direito Internacional, Curitiba, v.4, n.4, jul./dez.2006 
conferido após o decurso de processo administrativo, que se divide nas fases de depósito, publicação, exame e decisão. ${ }^{10}$

O processo inicia-se com o depósito, que deve conter o requerimento do que se pretende patentear, um relatório descritivo do objeto patenteado, as reivindicações que se faz, desenhos, resumo e o comprovante de pagamento das taxas. O depósito assegura a anterioridade da invenção.

O pedido do depósito não pode ser plural, devendo "se referir a uma única invenção ou a um grupo de invenções inter-relacionadas de maneira a compreenderem um único conceito inventivo". ${ }^{11}$ Em relação aos modelos de utilidade, é admitido que haja elementos distintos, adicionais ou variantes, "desde que mantida a unidade técnico-funcional e corporal do objeto."12

Uma vez realizado o depósito e aprovado no exame formal preliminar $^{13}$, o mesmo deve ser publicado, depois de passados 18 (dezoito) meses, ou antecipadamente, a requerimento do depositante. ${ }^{14}$ Segundo COELHO,

\footnotetext{
"a indispensabilidade da publicação, para o direito industrial, é fato que justifica, muitas vezes, o empresário preferir manter em segredo de empresa os avanços tecnológicos que seu departamento de pesquisa alcançou. Isso porque, uma vez tornada pública a reivindicação, qualquer pessoa terá acesso a esses avanços, e poderá deles se utilizar, cabendo ao empresário as providências para descobrir a utilização ilícita e bloqueá-la." ${ }^{15}$
}

Em seguida, decorridos ao menos 60 (sessenta) dias da publicação do pedido, passa-se à fase do exame ${ }^{16}$. Nesta fase, são apresentados possíveis impedimentos ao direito de patente pleiteado e juntados documentos necessários à regularização do processo.

O passo seguinte é o exame técnico, que, em síntese, analisa a patenteabilidade do pedido em face das qualidades técnicas do objeto. 0 exame técnico é relatado em parecer, que conclui pela concessão, ou não, da

\footnotetext{
${ }^{10}$ Quadro sintético e explicativo do processo de concessão de patentes encontra-se no Anexo I, retirado da obra de Ricardo NEGRÃO, "Manual de Direito Comercial e de Empresa", vol 1, 3" ed., São Paulo: Saraiva, pgs. 119-120.

${ }^{11}$ Art. 22 da Lei 9.279/96.

${ }^{12}$ Art. 23 da Lei 9.279/96.

${ }^{13}$ Art. 20 da Lei 9.279/96.

${ }^{14}$ Art. 30 da Lei 9.279/96.

${ }^{15}$ COELHO, Fábio Ulhoa. Curso de Direito Comercial, vol 1, 7ª ed.. São Paulo: Saraiva, 2003. p. 164.

${ }^{16}$ Art. 31, § $1^{\circ}$ da Lei 9.279/96.
}

Revista Brasileira de Direito Internacional, Curitiba, v.4, n.4, jul./dez.2006 
patente, podendo, ainda, exigir mais informações ou documentos do depositante antes de proferir o resultado. ${ }^{17}$

Se o parecer for favorável à concessão, faz-se o pagamento das taxas e finalmente expede-se a carta-patente, título hábil para comprovação do direito à patente.

O prazo de vigência da patente será de 20 (vinte anos) se de invenção, e de 15 (quinze) anos se de modelo de utilidade, contados da data do depósito. Contudo, se o processo de concessão for demasiadamente longo, é garantida a vigência da patente por 10 (dez) anos, se de invenção, e por 7 (sete) anos, se de modelo de utilidade, contados desde a data da emissão da carta-patente.

Em contrapartida, caso ao final do processo o parecer seja desfavorável, abre-se prazo para manifestação do interessado, que pode oferecer recurso. Ressalta-se que em todas as fases, inclusive no recurso, o órgão administrativo pode fazer exigências que, se não cumpridas, acarretam no arquivamento do processo e na não concessão da patente.

Após a narrativa deste extenso trâmite, percebe-se que o próprio processo de concessão das patentes paradoxalmente pode ser um grande empecilho à efetiva concessão das mesmas. A propósito, cita-se:

\footnotetext{
"Urge rever a questão do custo dos serviços, da eficiência do exame dos pedidos e do tempo para concessão dos registros, certificados e patentes. (...) Nos faltaram dados empíricos do tempo de tramitação dos pedidos de registro, principalmente da patente, que se estima em torno de sete anos.

Embora não tenhamos colhido os dados sobre o valor cobrado pelos serviços públicos da propriedade intelectual, o certo é que o acesso ao INPI é bastante restrito para uma quantidade enorme de empresas pequenas e para muitos centros de P\&D brasileiros. Quase impossível quando se necessita uma patente em muitos países. (...)

Outro ponto, que pode ser analisado conjuntamente, é o exame e tempo do tramite dos pedidos de registros, que requerem exame de novidade e de exigências legais que aponta para um gargalo. (...) Os dados estatísticos permitem concluir, empiricamente, que há um volume de requerimentos que não condiz com o número de funcionários e nem com o espaço físico de atendimento e arquivo.

Argumentamos, também, que é impossível o desenvolvimento nacional sem uma resposta mais rápida às solicitações de propriedade intelectual. Muitos produtos entram e saem rapidamente das prateleiras do supermercado. Muitas empresas aparecem e desaparecem. A demora impede um aproveitamento racional das potencialidades da propriedade intelectual, principalmente no âmbito da concorrência entre pequenas empresas, que são as mais
}

${ }^{17}$ Art. 35 da Lei 9.279/96.

Revista Brasileira de Direito Internacional, Curitiba, v.4, n.4, jul./dez.2006 
prejudicadas e também, as que geram uma grande soma de pequenas riquezas e o sustento da nação."18

\section{NULIDADE DA PATENTE}

Segundo o art. 46 da Lei 9.279/96, "é nula a patente concedida contrariando as disposições desta Lei", abrangendo tanto as disposições materiais atinentes à patenteabilidade da invenção, como os requisitos formais do processo de concessão da patente.

A nulidade poderá ser parcial, incidindo apenas sobre parte das reivindicações, persistindo as demais como plenamente válidas. Os efeitos da nulidade retroagem desde a data do depósito do pedido.

A nulidade pode ser argüida em procedimento administrativo ou processo judicial. Se por meio administrativo, o processo deve ser instaurado no prazo de seis meses contados da concessão da patente, ao passo que a ação judicial pode ser proposta a qualquer tempo durante a vigência da patente. $O$ processo judicial de nulidade de patente tem algumas características especiais: o prazo para apresentação da defesa do réu (titular da patente) é de 60 (sessenta) dias; a ação deve ser proposta na Justiça Federal; e o INPI, quando não for autor, deve necessariamente ser chamado para intervir no processo.

\section{CESSÃO}

A patente ou seu respectivo pedido de depósito podem ser cedidos onerosamente a terceiros.

"A cessão do direito industrial é o contrato de transferência da propriedade
industrial, e tem por objeto a patente ou registro, concedidos ou
simplesmente depositados. A cessão pode ser total, quando compreende
todos os direitos titularizados pelo cedente, ou parcial. Esta última pode se

18 PIMENTEL, Luiz Otávio. Propriedade intelectual e desenvolvimento, pgs.55-56. in CARVALHO, Patrícia Luciane (coord.). Propriedade Intelectual - Estudos em Homenagem à Professora Maristela Basso, Curitiba: Juruá, 2005.

Revista Brasileira de Direito Internacional, Curitiba, v.4, n.4, jul./dez.2006 
limitar quanto ao objeto (cede-se parte das reivindicações depositadas ou patenteadas, por exemplo) ou quanto à área de atuação do cessionário (tranfere-se o direito de exploração econômica com exclusividade dentro de certo país, por exemplo). Não há cessão temporalmente limitada da propriedade industrial, e não apenas de autorização de seu uso". ${ }^{19}$

Os efeitos da cessão, se feita por instrumento particular, operam somente entre as partes, ao passo que se houver anotação da cessão no INPI, serão produzidos efeitos erga omnes.

\section{LICENÇA}

Instituto próximo da cessão é o da licença. Na licença, a titularidade da patente não é transferida, conferindo ao licenciado apenas o direito de exploração do objeto da patente. Este direito pode ser dotado de exclusividade, se assim convencionarem as partes.

Aos efeitos da licença aplica-se a mesma sistemática da cessão: se o instrumento que confere a licença é averbado no INPI, o direito é oponível a terceiros, caso contrário, somente gera efeitos entre as partes.

Como na licença apenas a exploração da patente é transferida, mas não a propriedade em sua plenitude, pode ocorrer de uma das partes vir a aperfeiçoar a invenção ou modelo, gerando um possível conflito entre as partes, que poderiam alegar, uma em relação à outra, enriquecimento sem causa, por se beneficiarem sem justa causa às custas do aprimoramento realizado pelo outro. Este possível conflito, entretanto, foi previsto na Lei de Patentes que dispõe, no art. 63, que "o aperfeiçoamento introduzido em patente licenciada pertence a quem o fizer, sendo assegurado à outra parte contratante o direito de preferência para seu licenciamento", encerrando, assim, eventual disputa por critério valorativo de indenização.

\section{LICENÇA COMPULSÓRIA}

A lei brasileira admitiu o instituto da licença compulsória, que retira do titular o direito de exclusividade da exploração, conferindo-Ihe a terceiro, sem

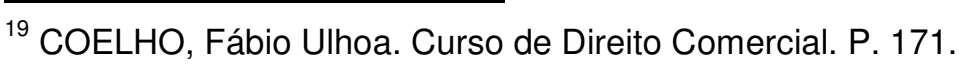

Revista Brasileira de Direito Internacional, Curitiba, v.4, n.4, jul./dez.2006 
onerosidade e independentemente da autorização do titular, para que explore o objeto da patente, em virtude do interesse público.

\begin{abstract}
"A tutela do interesse público nem sempre pode ser satisfeita através do direito exclusivo que a lei outorga ao titular da patente, pois a proteção deste interesse muitas vezes depende da forma pela qual o titular faz uso de seu direito.

Quando existe conflito entre interesse público e o interesse privado do titular da patente, o vigente sistema internacional de proteção aos direitos de propriedade intelectual permite que o Estado utilize-se de determinados instrumentos jurídicos para solucionar o conflito público/privado, dentre os quais destaca-se a licença compulsória." ${ }^{20}$
\end{abstract}

A mitigação do direito de propriedade, no âmbito das patentes, inserese no contexto geral da criação de limites à propriedade privada, que deve obrigatoriamente obedecer a sua função social, conforme salienta Tatyana FRIEDRICH:

\footnotetext{
"Conceitualmente, a patente não é direito absoluto, ao contrário, desde sua origem obedece a limitações e condições: territorialidade, prazo de vigência, novidade, atividade inventiva, aplicação industrial, possibilidade de salvaguardas para equilibrar direitos e obrigações e, no caso do Brasil, do mandamento constitucional de subordinação da propriedade, inclusive intelectual, à sua função social.,"21
}

Os limites da função social das patentes, são dispostos nos artigos 68 e seguintes da Lei oํ 9.279/96, que trazem as hipóteses ensejadoras da licença compulsória, as quais referem-se, basicamente, ao abuso de direito ou de poder econômico; a não exploração e fabricação do objeto da patente em território nacional; e a comercialização que não satisfaça as necessidades do mercado.

O intuito do instituto é o de proporcionar a fabricação local e o desenvolvimento nacional, com transferência de tecnologia e geração de

\footnotetext{
${ }^{20}$ GUISE, Mônic'a Steffen. O Requisito de Exploração Local do Objeto da Patente: uma análise da legislação no contexto internacional. P. 157. in: CARVALHO, Patrícia Luciane (org.). Propriedade Intelectual - Estudos em Homenagem à Professora Maristela Basso. Curitiba: Juruá, 2005.

${ }^{21}$ FRIEDRICH, Tatyana Scheila; FONSECA, Karla Closs. Regulamentação da Propriedade Intelectual: uma análise crítica. P. 73. in: CARVALHO, Patrícia Luciane (org.). Propriedade Intelectual - Estudos em Homenagem à Professora Maristela Basso. Curitiba: Juruá, 2005.
}

Revista Brasileira de Direito Internacional, Curitiba, v.4, n.4, jul./dez.2006 
empregos. Caso o titular não consiga, por motivos juridicamente relevantes, fabricar no Brasil o objeto da patente, e necessite importá-lo, a importação não é protegida pela exclusividade da patente, podendo qualquer interessado fazêla.

O pedido de licença compulsória é seguido de um processo administrativo, no qual é dada ao titular a oportunidade de se defender. Nos pedidos fundados em abuso de direito ou de poder econômico, cabe ao requerente provar tais alegações. Todavia, nas demais hipóteses, inverte-se 0 ônus da prova, cabendo ao próprio titular (réu) o ônus de provar a efetiva exploração, fabricação e comercialização do objeto da patente.

\section{PATENTES E RELAÇÃO DE EMPREGO}

A Lei de Patentes dispõe sobre a titularidade das patentes nos casos em que a invenção é realizada por empregado. São previstas três situações distintas, que geram obrigações entre empregado e empregador.

A primeira ocorre quando o trabalho intelectual que deu azo à invenção é objeto do contrato de trabalho. Nestes casos, a lei confere ampla defesa dos interesses do empregador, a quem é conferida a propriedade da patente, sem que deva haver qualquer tipo de remuneração extra ao empregado, pois a retribuição pelo trabalho intelectual seria aquela paga em forma de salário. Além disso, qualquer tipo de gratificação ou participação nos ganhos econômicos decorrentes da invenção não se incorpora ao salário. A proteção do empregador estende-se inclusive para além da relação de emprego, presumindo-se como feita na vigência do contrato de trabalho a patente requerida pelo empregado até um ano após a extinção do vínculo.

Em contrapartida, em situação oposta, quando o trabalho intelectual que gerou a invenção não tem relação alguma com o contrato de trabalho, é garantida ao empregado a titularidade da patente, sem qualquer participação do empregador.

Há, ainda, uma terceira situação, na qual o trabalho intelectual que desencadeou a invenção é favorecido por circunstâncias do contrato de 
trabalho, ou seja, há utilização de recursos, dados, meios, materiais, instalações ou equipamentos da empresa pelo empregado, sem que a atividade inventiva seja objeto do contrato de trabalho. Nestas hipóteses, a propriedade da patente será comum, mas garante-se ao empregador o direito exclusivo de licença de exploração, assegurado ao empregado a justa remuneração. Caso o empregador não venha a utilizar o direito de exclusividade da licença, deixando de explorar a patente por mais de um ano, contado da data da concessão da patente, a mesma passará a ser de propriedade exclusiva do empregado.

A interpretação destas situações deve levar em conta que a Lei de Patentes desconsidera a real natureza do vínculo entre empregado e empregador, não sendo necessária a existência de relação empregatícia, nos moldes da CLT. O termo "empregado" é utilizado de forma ampla, referindo-se a qualquer pessoa contratada, seja numa relação típica de emprego, um estagiário, um prestador de serviços ou até mesmo uma empresa que preste serviço à outra. Do mesmo modo, o termo "empregador" também deve ser lido em seu sentido lato, referindo-se a qualquer pessoa contratante, aplicando-se as regras inclusive à Administração Pública.

\section{EXTINÇÃO DAS PATENTES}

Nos termos do art. 78 da Lei 9.279/96, "a patente extingue-se: I- pela expiração do prazo de vigência; II, pela renúncia de seu titular, ressalvado o direito de terceiros; III - pela caducidade; IV - pela falta de pagamento da retribuição anual" e V - pela inexistência de representante legal no Brasil, se o titular tem sede ou domicílio no exterior.

Dentre estas hipóteses, merece mais atenção a da caducidade, que ocorre se passados dois anos da concessão da primeira licença compulsória sem que o abuso ou desuso da patente (que ensejaram a licença) não tiver sido sanado.

Revista Brasileira de Direito Internacional, Curitiba, v.4, n.4, jul./dez.2006 
Uma vez extinta a patente, o seu objeto cai em domínio público. Assim, qualquer pessoa poderá utilizar o invento patenteado livremente, sem ter que responder por quaisquer ônus ao titular.

\section{CONCLUSÃo}

A lei brasileira se insere no sistema internacional de proteção da propriedade intelectual, mantendo as garantias mínimas dadas pelas convenções internacionais. Justamente por seguir as diretrizes externas ela é freqüentemente criticada, pois estaria mais adaptada às necessidades dos países desenvolvidos, que são os grandes depositários das patentes, do que a um país como o Brasil, cuja produção científica é relativamente baixa.

Apesar de fazer uma constatação válida, esta crítica não aponta uma solução plausível para o problema, pois ao que tudo indica, o não reconhecimento dos direitos sobre a propriedade intelectual é um retrocesso que pode afetar negativamente o acesso à tecnologia. Ademais, a lei brasileira possui mecanismos para evitar abusos de direito ( $v . g$. a licença compulsória), assim como para difundir as informações depositadas, impulsionando o desenvolvimento científico.

Apesar do contraponto, de fato, a lei brasileira acaba por proteger mais os interesses dos países desenvolvidos do que os interesses nacionais. No entanto, isto não se deve à lei em si mesma, em abstrato, mas à sua aplicação prática. Em teoria, a lei brasileira é capaz de proteger o valor econômico das patentes, sejam elas estrangeiras ou nacionais. Todavia, o principal problema encontra-se na utilização do aparato legal. O que ocorre é que o procedimento para concessão das patentes é lento e dispendioso, e além disso são relativamente poucos os pedidos de depósito realizados por universidades e empresas brasileiras. Por isso, uma mudança na lei de patentes não necessariamente traria benefícios, visto que, em abstrato, ela obedece a um sistema que cria direitos, permite a circulação de riquezas e de informações e 
veda os abusos. É necessário, no entanto, que sejam feitos investimentos em pesquisa e desenvolvimento, bem como na aceleração dos trâmites burocráticos, para que haja geração de desenvolvimento científico e econômico no âmbito nacional.

\section{REFERÊNCIAS}

COELHO, Fábio Ulhoa. Curso de Direito Comercial, volume 1, $7^{\mathrm{a}}$ ed. São Paulo: Saraiva, 2003.

DELGADO Maurício Godinho. Curso de Direito do Trabalho. 3 ed. São Paulo: LTr, 2004.

FRIEDRICH, Tatyana Scheila; FONSECA, Karla Closs. Regulamentação da Propriedade Intelectual: uma análise crítica. p. 73. in: CARVALHO, Patrícia Luciane (org.). Propriedade Intelectual - Estudos em Homenagem à Professora Maristela Basso. Curitiba: Juruá, 2005.

FRIEDRICH, Tatyana Scheila; RAMINA, Larissa. Direito Internacional e Direito Interno nas Relações de Propriedade Intelectual. O Acordo TRIPS e a Lei Brasileira de Patentes. In MENEZES, Wagner (org.). O Direito Internacional e $O$ Direito Brasileiro - Homenagem a José Francisco Rezek. ljuí: Ed. Unjuí, 2004.

GUISE, Mônica Steffen. O Requisito de Exploração Local do Objeto da Patente: uma análise da legislação no contexto internacional. p. 157. in: CARVALHO, Patrícia Luciane (org.). Propriedade Intelectual - Estudos em Homenagem à Professora Maristela Basso. Curitiba: Juruá, 2005.

NEGRÃO, Ricardo. Manual de Direito Comercial e de Empresa, vol 1, $3^{\underline{a}}$ ed. São Paulo: Saraiva, 2003.

Revista Brasileira de Direito Internacional, Curitiba, v.4, n.4, jul./dez.2006 
PIMENTEL, Luiz Otávio. Propriedade Intelectual e Desenvolvimento. in:

CARVALHO, Patrícia Luciane (org.). Propriedade Intelectual - Estudos em Homenagem à Professora Maristela Basso. Curitiba: Juruá, 2005.

PIMENTEL, Luiz Otávio. Propriedade Intelectual e universidade: aspectos legais. Florianópolis: Fundação Boiteux, 2005.

SILVEIRA, Newton. A Propriedade Intelectual e as Novas Leis Autorais, $2^{\mathrm{a}}$ ed. São Paulo: Saraiva, 1998.

SOARES, José Carlos Tinoco. Lei de Patentes, Marcas e Direitos Conexos. São Paulo: RT, 1997. 